\title{
Design and Development of Smart Campus System Based on BIM and GIS
}

\author{
Yunxia Jiang ${ }^{1, a}$ \\ ${ }^{1}$ Shanghai Sanda Institute, Shanghai, China 201209 \\ ayxjiang@sandau.edu.cn
}

Keywords: campus, BIM, GIS,system.

Abstract. This paper discusses the design and development of the campus system from the following aspects: the overall structure of the system, the functions of each subsystem, and the key skills and difficulties.

\section{Introduction}

Campus is like a miniature version of the city, which is a complex ecological system, which need to carry the campus of teaching, scientific research, management, staff and students. The construction technology of smart campus mainly includes the network communication technology, the Internet of things, big data and cloud computing, GIS and BIM, social computing and other related techniques, which are the basis of the construction of the smart campus, and which will bring new challenges[1]. Integration of technology will be a priority for the construction of smart campus. The application of BIM and GIS will make the application of Internet of things technology in the construction of campus intelligence more convenient and intelligent. BIM (Building Information Modeling) technology is the guarantee of smart campus health operation. BIM technology for smart campus, the intelligent Building is the core of the "smart". Geographic Information System (GIS) technology is the basis of geometry and spatial relationship of smart campus. GIS technology is combined with geography and cartography, which mainly used for the input, storage, query, analysis and display of campus geographic data, special treatment of Campus Geographic data. BIM will provide GIS to improve the complexity of three-dimensional data. The integration of GIS and BIM will become the new challenge of GIS. The integration of BIM and GIS will also bring new ideas and methods for the construction of smart campus.

\section{Overall Design Structure of the System}

The smart campus system will be constructed by using networking technology, database technology, GIS technology, BIM technology and visualization technology and the smart campus system will be based on all kinds of resources and based on the integration, classification means.

There are spatial data and attributes data in the system. Spatial data are mainly composed of point, line and surface files. Point files include housing, facilities etc.. Line files contains roads and rivers etc.. The surface files contains river, teaching areas, students accommodation areas, office areas etc.. In addition, the spatial data include the basic geographic maps, the campus plan maps, the layered building plan maps and so on. The layered building plan maps are corresponding to the corresponding attributes information. The attributes data include various departments, financial management information, office location information, student status information, student employment information library collection information and other management information.

\section{System Composition}

The system will be constructed in order to adapt to campus construction goal in the new era, in order to facilitate the teaching, scientific research, management, and campus information comprehensive information management. Based on the principle of feasibility, the compositions of the intelligent campus system are shown in the following. 
Basic Information Subsystem.In the basic information subsystem, the amount of data in the database is large and the data type is complex. In order to facilitate the storage, management, operation and expansion of the future, the campus basic information system data types are divided into the following sections: basic information database, control point database, data elevation model database, attribute database, file database. Specifically, there is teaching building spatial data information, road data information, room information, data of green space data, underground pipeline data information and teaching unit information, office information, student information, teacher information, student dormitory management department data information, equipment information and attribute data in the system. This subsystem is the basis for the successful development of the following subsystems[2].

Building Equipment Management Subsystem. On the basis of technology Internet of Things and RFID, combined with BIM and GIS technology, the property data and spatial data of all kinds of buildings and equipment are unified in the building equipment management system. The electronic map records and inquiries of the various equipment of a variety of buildings (such as canteens, teaching buildings and campus building) must be able to provide in this subsystem. At the same time, in this system, we can clearly understand the real-time operation of campus buildings and buildings equipments, and we can make a reasonable operation of construction equipment, and we can reduce maintenance work and achieve energy saving and environmental protection management. The location of the building and equipment will achieve geographical positioning by GIS technology. The spatial model of the building and equipment can be real-time monitored by BIM technology [3].The use of this system requires the integration of BIM and GIS technology.

Land use management subsystem. The problem of school land has always been a bottleneck in the development of the school. So we should pay more attention to the management of school land. Land management subsystem will be able to choose the appropriate location of the new infrastructure in the campus. And the information of the campus lands can be analyzed in this subsystem.

In order that the policymakers reasonably choose the campus site, we can carry out the spatial statistical analysis by use data of the campus land area and by the data among the various infrastructures and we can make use of the campus with the calculation of land resources to achieve maximum results. This system can provide decision basis for the decision maker of the campus, and play the role of the decision support system.

Pipeline management subsystem.The campus pipeline like the city's pipeline are roughly divided into seven categories: water supply pipeline, drainage pipeline, gas pipeline, heat pipeline, factory pipeline (in the city in the corresponding pipeline for industrial electricity), power pipeline and telecommunications pipeline [4]. Some campus has set up campus network, so it will have photoelectric cable.

The pipelines are distributed in space, and they are often arranged, perplexing arranged in a crisscross pattern together to form a pipeline network.

Pipeline management subsystem will be able to achieve the storage and management of pipeline attribute information; pipeline information query, statistical analysis (such as fault impact analysis). Pipeline management subsystem will be able to visually view the relative position among the pipelines on the computer. Therefore, the system will be able to ensure that after the accident the management of the line can be quickly analyzed and handled with the help of the Internet of things technology. And this system will be able to provide assistance to the campus planning, construction and management of decision support.

Greening and road engineering subsystem.Campus greening is an important work in campus environmental management. There is a complete record of campus greening in this system. And the damage and maintenance of campus will be a good management, analysis and statistics.

There is a complete record of campus road in this system. The campus roads and landscaping will be unified management in this system. This subsystem should have a large amount of historical data and a series of data processing and analysis tools. Through the collection, storage, processing and analysis of relevant data in this system, it can provide useful information for construction planners, and provide technical support for decision makers in the process of maintenance decision making. 
Auxiliary decision subsystem.By the second development function of GIS, combined with other development language, firstly, we can integrate the educational system, the existing information management system, financial system and network system. And we can design and develop the campus GIS system. Finally the safe, reliable and stable intelligent campus system will be generated . Therefore, this system will play an important role in the school's teaching and scientific research management, staff management, student management, campus planning and development.

For example, combining the student information and maps, we can realize the mutual check and maintenance of student information and the location of the dormitory, so as to improve the students' archives information management and realize geographic positioning of students archives information. In this system, by means of statistical analysis of the information in the chart, the complex characteristics of campus space development and change will be reflected. Therefore, in this system, we can achieve a variety of architectural programs, from which to choose the most suitable solution for campus construction, so as to achieve the purpose of future campus development planning.

Predictive analysis subsystem.The general steps of prediction: (1) to determine the predicted target; (2) the collection and analysis of relevant statistical data and historical data; (3) choosing a prediction method; (4) establishing a prediction mathematical model; (5) through the analysis and evaluation, prediction of initial measured value; (6) revising forecast value. For example, according to the flow of personnel and the introduction of talent, the leadership of the school can predict the housing conditions of teachers in recent years. According to the size of the school enrollment, student dormitory information, school land situation, the school's leadership can predict the student accommodation requirements in recent years. In this forecast subsystem, we will use the linear programming and analytic hierarchy process to establish the mathematical model.

System Function.In order to facilitate the input of information, the rapid extraction of data, and the ability to conduct predictive analysis and decision support simulation under the support of multiple information sources, each subsystem will be able to achieve the following functions: data input function, query function, statistics function, revising and updating function, data editing and output function, the function of system management and spatial analysis function etc..

\section{Key technologies and difficulties}

Data acquisition and input.According to foreign statistics, in the cost of GIS, data acquisition costs accounted for the total cost of $60 \% \sim 70 \%$. Data is the blood of the intelligent campus system, so how to get the information of the system and how to collect the data is one of the key points of the system. When collecting data, the collection of attribute data and spatial data should be separated. The attribute data mainly includes the whole school staff data, all the student data, the books data, archives data, the building data, the infrastructure data and the attributes data of the various equipments. By use of the Internet of things technology and RFID technology, we can make buildings, infrastructure and all kinds of instruments and equipment, etc with qr code in order to facilitate the management of the database and update. After the access to the campus of two-dimensional flat and figure, we will import it in the GIS software and give it the space coordinate information and projection information. That will contribute to generate digital topographic map and realizing the two-dimensional plane figure and attribute information. In this system, we can make use of GIS software to process information of buildings and infrastructure and we can use BIM technology for $3 \mathrm{~d}$ modeling software. Then the model will be a variety of analysis and operation. Finally the model of spatial information and attribute information can be associated with it.

Coding design. The planning department system is mainly used in the campus, but also it is suitable for office, branch office, teachers and students etc.. Computerized campus resources management is different from the previous manual management mode. Its main characteristic lies in the various types 
of data, so it must have a scientific encoding system to operate more effectively. Therefore, the coding design is one of the key points of the system[5].

Integration of BIM technology and GIS Technology.With the help of BIM technology and GIS technology in Intelligent Campus Modeling, the model will be more accurate and powerful. But, the integration of BIM technology and GIS technology is not a simple combination of the two technologies. Instead, we need to build an integrated model. So we need to import data into the GIS software BIM, while the GIS data in BIM. In this way, BIM data as an important data source of geographic information system is used to generate intelligent campus model. The data in GIS can be used as the basic data of the new building information model. The establishment of BIM and GIS integrated intelligent campus model can not only improve the level of information management and application ability of digital campus, but also realize the innovation and leap forward development of GIS technology and BIM technology.

Establishment of assistant decision model.Auxiliary decision model is a spatial analysis and mathematical model based on the purpose of decision making. In this system, the spatial analysis is based on the data of the campus geographic information database. We can analyze the campus information according to the relevant mathematical model and the results of the spatial analysis. The establishment of mathematical model will greatly enhance the function of intelligent campus system.

\section{Conclusions}

BIM and GIS integration has gradually become the focus of digital city and infrastructure construction field. However, from the past two technology development point of view, that BIM and GIS will be each other into one's own is still some difficulty.The integration of BIM and GIS is still in its infancy, and there is no attempt and application in the campus information management. Therefore, this paper based on BIM and GIS intelligent campus system design and system construction plan has certain theoretical and practical significance.

\section{References}

[1] Zhixuan Yang,Ping Gao,Hao Yun.Application Research on BIM in Digital Campus Building.Engneering Economy. Vol.26(2016),p,44-48.In Chinese.

[2] Xinying Li,Feng Li.University Digital Campus Geographic Information System Research and Analysis. Science \& Technology Vision. Vol.27(2013),p,32-33.In Chinese.

[3] Narushige Shiode 3D Urban Models: recent developments in the Digital Modeling of Urban Environments in Three-Dimension. Published in GeoJournal. Vol.52(2001),p,263-269.

[4] Alexander K, Sigid B.3D GIS for Urban Purposes. GeoInformatica. Vol.1(1998),p,99-103.

[5] Xiaogang Feng,Dongmei Tang. Design and Realization of the Digital Campus of Xi'an University of Architecture and Technology. GeoSpatial Information. Vo1.8(2010)p,101-104.In Chinese. 